\title{
New development: Are social impact bonds (SIBs) viable in Italy? A new roadmap
}

\section{Irene Bengo and Mario Calderini}

\author{
This paper presents a roadmap to support the development of SIBs in Italy. \\ Current barriers and opportunities are explained. SIBs should be piloted in areas \\ where the cultural, ideological, technical and governance barriers are low. \\ Accurate measurement systems will be necessary and an effective governance \\ structure needs to be agreed. With careful piloting and follow-up, the SIB model \\ could be a solution to welfare and public service funding in Italy.
}

Keywords: Impact finance; Italy; social impact bonds (SIBs); welfare withdrawal.

This article discusses the viability of social impact bonds (SIBs) in Italy. Over the past few years, SIBs have been promoted as new form of privatepublic partnership (PPP) to finance social programmes (Jackson, 2013). SIBs are not conventional bonds (Warner, 2013); they are hybrid tools with elements of either equity or debt, aimed at supporting preventative interventions through a pay-by-results contract (Liebman and Sellman, 2013). Investors, through a financial intermediary, pay for a given social service which a government considers a priority. If the service achieves the social goals agreed upfront, the government will remunerate the investors; if not, they lose their investment.

The best-known SIB is the UK's Peterborough Prison SIB, which was launched in 2010 by Social Finance. The target in this case was to reduce the recidivism rate among exoffenders by $10 \%$ over a five-year period. If these performance goals are reached, the savings achieved in terms of reincarceration will be used to pay back the investors with a rate of return. If not, the investors will lose some or all of their money.

Soon after the Peterborough Prison SIB was set up, $25 \mathrm{SIBs}$ were commissioned in other countries, such as the USA, Australia, Canada, Belgium, the Netherlands and Germany (Social Finance, 2014; Wilston, 2014). Moreover, many countries such as Ireland, Israel, South Korea, Japan, France, Italy and Scotland are showing signs of interest in the SIB model and some international organizations are considering using SIBs to finance specific projects in developing economies. The growing interest in this financial instrument is the result of the after-effects of the financial crisis in 2008. New and pressing social needs were generated by the crisis as unemployment grew. At the same time, public sector spending had to be reduced to contain public debt and deficits (Karanikolosetal., 2013). These converging pressures created an urgent need to modify the approach to the provision and purchase of social services, forcing policymakers to turn to third and private sector organizations to deliver services (Millar, 2012). At the same time, the financial markets began to change with a new generation of investors emerging ('social investors' or 'social impact investors') who want to see social impact as well as financial returns on their investments (BuggLevine and Emerson, 2011).

Despite the widespread interest in the SIB model, a SIB's feasibility and effectiveness is dependent on the objectives, the target beneficiaries and the related impact measurement in the context of the social, economic and institutional environment of the country involved. The SIB model relies on the involvement of a diverse range of actors, including social enterprises and non-profit organizations. These actors are investible subjects, i.e. the potential recipients ofimpact investing, and their aggregate demand for capital is the potential space of opportunity for the emerging SIB market. A balanced analysis between the supply of capital (represented by SIBs) and the availability of adequate investment opportunities (Global Impact Investing Network, 2011) is an important measure of whether or not a SIB model will work. A country's legislative framework is also highly significant (Wilston, 2014).

The Italian context: barriers and opportunities for the development of SIBs 
Italy is currently facing financial challenges that are forcing policy-makers to look for alternative ways of paying for social services. SIBs are one of models being investigated.

\section{Demand-side issues}

Analysing the demand side of a potential SIB market, the Italian context is now experiencing a remarkable growth in the so-called 'social economy' (associations, foundations, social cooperatives, charities, social enterprises). Thelevel of maturity of these organizations, however, may preclude them from SIB financing:

- First, they are highly dependent on public financing or grants/donations. They are generally 'low capitalization', organizations lacking adequate guarantees and with difficult access to credit (Zamagni, 2011).

- Second, they generally lack sound entrepreneurial and managerial skills (Venturi and Zandonai, 2012). In the SIB model, service providers need the skill-sets and competencies to deliver a social service on a reasonably large scale (i.e. they need the capacity to replicate the procedures and interventions to generate more and more social impact and involve a greater number of potential beneficiaries).

For the SIB model to be viable in Italy, it would be helpful for the Italian legislation on social enterprises (Dgl. 155, 2006) to be revised so that social enterprises are classed as 'entrepreneurial models'. Safeguards may be necessary to ensure that capitalization and fundraising do not undermine the social mission of social enterprises.

\section{Supply-side issues}

On the supply side, the public sector plays a fundamental role because it acts as the commissioner of public services, and can benefit from any savings generated by using the SIB model. This issue is complicated because a number of factors affect savings. The results of a SIB intervention do not necessarily affect only one government agency (Fox and Albertson, 2011). In the Italian case, public services are highly fragmented, both in terms of geographical distribution and between different levels of government. Also, the Italian public sector accounting rules require a cost item to be related to a specific service and the administration is constrained in the ways it can 'use' any savings (the 'stability pact'). There are constraints in place that prevent further investment even when there is cash available, which makes it very difficult to set up a SIB scheme.

Also relevant to the local context, another barrier is a the lack of tools available to measure the social value of services (something that needs to be known to determine the return rate of a SIB).

How social impact should be measured is currently being debated at the international level (Bengo et al., 2016). This is an important problem, because private investors need a reliable set of tools to evaluate and measure their results. Italy is at an earlier stage in this than is the UK. In the UK, some measurement systems have been developed and shared between the public and private sectors, for example the 'social return on investment' (SROI). The SROI is defined as a form of adjusted cost-benefit analysis that takes into account, in a holistic way, different types of impacts that social programmes may determine (Rotheroe and Richards, 2007).

The measurement issue is not simply a technical one: it is also a governance problem. Regulation is necessary to protect societies from social enterprises with overly 'investor-centred' approaches (Fox and Albertson, 2011). Governments need to ensure that stakeholders cannot manipulate the results of measurement systems (Jackson, 2013).

A final consideration relates to the level of maturity of social impact finance in Italy. To date, only simpler types of bonds have been issued, in which the income (or a fraction of it) has been used to provide the social sector with donations or other forms of financing.

\section{Conclusions}

SIBs, although a solution in some areas, cannot be used for all social services. This is because of ideological and cultural barriers and, most important, because sometimes there are very good reasons for direct public funding. Nevertheless, there are areas in which such barriers are lower and the conditions more favourable, where radical innovation is needed and public spending is retreating more rapidly: for example elder care, disease prevention, and performing arts. We think that SIBs should be piloted in the areas in which cultural, ideological, technical and governance barriers are lower, thus allowing direct public intervention to be concentrated in areas where SIBs schemes would be difficult and, most importantly, where direct public funding is more appropriate. While we think that ideological and cultural barriers will take a long time to overcome in Italy, technical and governance issues are more easily solved.

The first issue to solve is related to new indicators and assessment tools for evaluating public policies. Italy needs to align to international trajectories, by promoting consistent 
measurement systems and designing a governance structure to manage the measurement infrastructure, ensuring impartiality and transparency. In this respect, the re-constitution of a third sector agency, under the new Enabling Act for the Reform of the Third Sector, would provide a supervisory body to examine transparency and impartiality. As well requiring a dedicated governance structure, the new procurement system needs to be embraced by both the third and public sectors. It is important that all players understand that payfor-success instruments and the related measurement systems change risk allocation, shifting the risk from being entirely on the public administration that procures the service to being shared by the administration, the service providers, investors and intermediaries.

Second, the public sector could promote a roadmap, like Portugal's social innovation programme, to integrate social impacts in the economic system, in order to align demand for capital (social business) and supply (impact finance instruments). To do this, the government will need to provide technical support for social enterprises and encourage private sector organizations to consider social impact as a part of their investment strategy. To accelerate the development of a SIB market, the government should:

- Reduce administrative barriers and costs to make social impact investments available to institutional and private investors, by introducing a tax break for social impact investments.

- Review the legislation on social enterprises, by promoting a more inclusive vision that encompasses the traditional social economy (co-operatives and social co-operatives), along with new hybrid forms (profit-non-profit), such as multi-utility companies and community interest companies.

Two different positions are emerging in connection with SIBs in Italy. The first is an 'orthodox' position-the development of a SIB model that is compliant with the Anglo-Saxon SIB archetype, even though this approach is bound to clash with the characteristics of the Italian public finance system (cash budget and delegation system). The second position is less rigid, and looks to bypass the problems in the public finance system by creating hybrid payfor-success instruments. These instruments include very diverse solutions, such as bonds in which banks assume the risk of the intervention and the public sector does not need to budget for an investment based on potential future savings.

Italy needs now to develop some pilots, that need to be carefully followed, examined and studied in order to properly understand their advantages and disadvantages, against the background of the actual Italian playing-field.

\section{References}

Bengo, I., Arena, M., Azzone, G. and Calderini, M. (2016), Indicators and metrics for social business: a review of current approaches. Journal of Social Entrepreneurship, 7, 1, pp. 1-24.

Bugg-Levine, A. and Emerson, J. (2011), Impact investing, transforming how we make money while making a difference. Innovations, 6, 3, pp. 31-40.

Fox, C. and Albertson, K. (2011), Payment by results and social impact bonds in the criminal justice sector: new challenges for the concept of evidence-based policy? Criminology and Criminal Justice, 11, 5, p. 395-413.

Global Impact Investing Network (2011), Impactbased Incentive Structures, Aligning Fund Manager Compensation with Social and Environmental Performance (www.thegiin.org).

Jackson, E. T. (2013), Evaluating social impact bonds: questions, challenges, innovations, and possibilities in measuring outcomes in impact investing. Community Development, 44, 5, pp. 608616.

Karanikolos, M. et al. (2013), Financial crisis, austerity, and health in Europe. The Lancet, 381, 9874, pp. 1323-1331.

Liebman, J. and Sellman, A. (2013), Social Impact Bonds: A Guide for State and Local Governments (Harvard Kennedy School Social Impact Bond Technical Assistance Lab).

Millar, R. (2012), Social enterprise in health organisation and management: hybridity or homogeneity? Journal of Health Organization and Management, 26, 2, pp. 143-148.

Rotheroe, N. and Richards, A. (2007), Social return on investment and social enterprise: transparent accountability for sustainable development. Social Enterprise Journal, 3, 1, pp. 31-48.

Social Finance (2014), Fact Sheet: Introduction to Social Impact Bonds (www.socialfinance.org.uk).

Venturi, P. and Zandonai, F. (2012), L'impresa sociale in Italia. Pluralità dei modelli e contributo alla ripresa (Edizioni altreconomia).

Warner, M. E. (2013), Private finance for public goods: social impact bonds. Journal of Economic Policy Reform, 16, 4, pp. 303-319.

Wilston, K. E. (2014), New Investment Approaches for Addressing Social and Economic Challenges (OECD Publishing).

Zamagni, S. (2011), Libro bianco sul Terzo settore. Icon, 39 (Il Mulino). 
